Case Study

\title{
Simultaneous nitrogen and organic carbon removal in aerobic granular sludge reactors operated with high dissolved oxygen concentration
}

\author{
Gaetano Di Bella $^{*, a}$, Michele Torregrossa ${ }^{\text {a,b,1 }}$ \\ ${ }^{a}$ Facoltà di Ingengeria e Architettura, Università degli Studi di Enna "Kore", Cittadella Universitaria, 94100 Enna, Italy \\ ${ }^{\mathrm{b}}$ Dipartimento di Ingegneria Civile, Ambientale, Aerospaziale e dei Materiali Università di Palermo, Viale delle Scienze, 90128 Palermo, Italy
}

\section{H I G H L I G H T S}

- The study offers information about the carbon and nitrogen removal in granular SBR.

- The SND process was discussed under high dissolved oxygen concentration conditions.

- Different organic and nitrogen loading rate have been applied.

- Results show that even with high DO concentration $\mathrm{N}$ and $\mathrm{C}$ can be removed.

\section{A R T I C L E I N F O}

\section{Article history:}

Received 12 March 2013

Received in revised form 14 May 2013

Accepted 16 May 2013

Available online 22 May 2013

\section{Keywords:}

Aerobic granular sludge

Granule size

Nutrient removal

Feast-famine

SND process

\begin{abstract}
A B S T R A C T
Simultaneous nitrification and denitrification (SND) together with organic removal in granules is usually carried out without Dissolved Oxygen (DO) concentration control, at "low DO" (with a DO < 30-50\% of the saturation value, about $3-4 \mathrm{mg} / \mathrm{L}$ ) to promote anoxic conditions within the aggregates. These conditions can sometimes be in detrimental of the stability of the granules itself due to a lack of shear force. In this work, the authors achieved SND without oxygen control with big sized granules. More specifically, the paper presents a experimentation focused on the analysis of two Sequencing Batch Reactors (SBRs), in bench scale, working with different aerobic sludge granules, in terms of granule size, and high DO concentration, (with concentration varying from anoxic conditions, about DO $\sim 0 \mathrm{mg} / \mathrm{L}$, to values close to those of saturation, $>7-8 \mathrm{mg} / \mathrm{L}$, during feast and famine conditions respectively). In particular, different strategies of cultivation and several organic and nitrogen loading rate have been applied, in order to evaluate the efficiencies in SND process without dissolved oxygen control. The results show that, even under conditions of high DO concentration, nitrogen and organic matter can be simultaneously removed, with efficiency $>90 \%$. Nevertheless, the biological conditions in the inner layer of the granule may change significantly between small and big granules, during the feast and famine periods. From point of view of granule stability, it is also interesting that with a particle size greater than $1.5 \mathrm{~mm}$, after the cultivation start-up, the granules are presented stable for a long period (about 100 days) and, despite the variations of operational conditions, the granules breaking was always negligible.
\end{abstract}

(c) 2013 Elsevier Ltd. All rights reserved.

\section{Introduction}

The Sequencing Batch Reactor (SBR) with aerobic granular sludge represents a good alternative to conventional activated sludge plants (Abdullah et al., 2013). In particular, granular SBR systems guarantee high sludge settle-ability and excellent performance, with small space demand. The phenomenon of bio-granulation involves cell-cell interaction and includes physical, chemical and biological factors (Liu and Tay, 2006a; Adav et al., 2008). The products of this process are the biomass aggregates formed through self-immobilization of micro-organisms. More specifically, the

\footnotetext{
* Corresponding author. Tel.: +390935 536350.

E-mail addresses: dibella@idra.unipa.it, gaetano.dibella@unikore.it (G. Di Bella).

1 Tel.: +39 0913923896520 ; fax: +39 0916657749.
}

granules are constituted by dense clusters containing millions of organisms per gram, including within them different bacterial species that play different roles in wastewater treatment (Kim et al., 2008; Othman et al., 2013). Compared to conventional activated sludge flocs, the granules have a smooth texture, thick and very good settleability. Further, the granular sludge can efficiently operate with high levels of organic load, high Sludge Retention Times (SRTs) and variable operational conditions (Anuar et al., 2007; Yuan and Gao, 2010).

Another interesting aspect of this technology is the possibility of obtaining a successful removal of nutrients in a single reactor, because the conditions necessary for nitrification, denitrification and biological phosphorus removal are carried-out within the granules (Yang et al., 2003; Mosquera-Corral et al., 2005; de Kreuk et al., 2005; Chen et al., 2011; Coma et al., 2012). In fact, the 


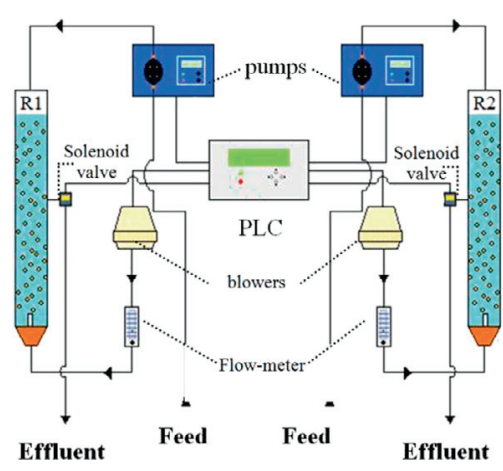

\begin{tabular}{cccc}
\hline Geometric features of the reactors & SBAR & SBBC & Unit \\
\hline cylinder height & 860 & 860 & $\mathrm{~mm}$ \\
riser height & 600 & - & $\mathrm{mm}$ \\
water table level & 690 & 640 & $\mathrm{~mm}$ \\
cylinder diameter & 90 & 90 & $\mathrm{~mm}$ \\
riser diameter & 54 & - & $\mathrm{mm}$ \\
volumetric exchange ratio & 50 & 50 & $\%$ \\
Reactor volume & 3.5 & 3.5 & $\mathrm{~L}$ \\
\hline
\end{tabular}

Fig. 1. The layout of the pilot plant and geometric features of $S B A R / S B B C$ reactor.

structure of a stable granule can be characterized by different layers, that allow organic carbon and nutrient removal in the same reactor. The presence of heterotrophic population can be observed in the inner part of the granules and, due to oxygen diffusion limitation inside the granules, it is possible to establish a denitrification process; in the middle layer, autotrophic biomass is dominant; in the outer layer, where oxygen and organic substances are highly available, aerobic heterotrophic growth occurs (Jin et al., 2008; Wan and Sperandio, 2009). Nevertheless, the thickness of each layer depends on oxygen and substrate penetration within the granule. Thus, the Simultaneous-Nitrification-Denitrification (SND) process is regulated by the oxygen gradient within the granule (Yilmaz et al., 2008). This depends basically on two aspects (Coma et al., 2012): (1) the Dissolved Oxygen (DO) concentration in the bulk liquid; (2) the granule sizes.

In general, there appears to be a general consensus that SND process within the granules can be optimized when a limited oxygen concentration is applied or a specific anoxic phase is performed (Beun et al., 2001; de Kreuk et al., 2007). Unfortunately, granules may break with low oxygen concentration and often it is impossible to obtain stable granules (Liu and Tay, 2006b, 2008). In particular, de Kreuk and van Loosdrecht (2004) affirm that oxygen concentration reduced to $40 \%$ of the saturation value ( $\mathrm{DO}<3-4 \mathrm{mg} / \mathrm{L}$ ) caused break-up of granules.

On the other hand, high concentrations of oxygen (with values close to those of DO saturation) may sometimes be required, especially when the granular sludge is used with other advanced technologies, for example with membranes bioreactor (Li et al., 2008). In this context, the granule sizes could have a more important role on the SND process, with reference to thickness variation of anoxic/aerobic zones within the granules. In particular, the different oxygen penetration inside a "big" granule, during feast and famine periods, can improve biological performance and reduce membrane fouling (Wei et al., 2011).

Bearing in mind these observations, the paper reports the analysis of the simultaneous organic and nitrogen removal obtained in two bench scale SBRs with different mean granule sizes (both greater than $1.5 \mathrm{~mm}$ after the cultivation period). The study aims to offer useful information about the optimization of nitrogen removal in an aerobic granular sludge reactor with "high" DO concentration.

\section{Methods}

\subsection{Pilot plant description}

Experiments were performed in two column-type aerobic granular sludge sequencing batch reactors. Actually, the granular sludge cultivation was carried-out with a Sequencing Batch Airlift Reactor (SBAR). Successively, after 102 days, the configuration of $\mathrm{R} 1$ and R2 was changed to Sequencing Batch Bubble Column (SBBC) reactor (Beun et al., 2002).

Both reactors had a working volume of $3.5 \mathrm{~L}$ and a filling height of $74 \mathrm{~cm}$. The riser of SBAR configuration was $60 \mathrm{~cm}$ height with an internal diameter of $5.4 \mathrm{~cm}$ and was positioned at a distance of $3 \mathrm{~cm}$ from the bottom of the reactor. Other, geometric features were reported in Fig. 1, where a scheme of plant installation is reported.

The effluent was withdrawn using an electromagnetic valve located at $37 \mathrm{~cm}$ from the bottom of the reactor and so the volumetric exchange ratio was 50\%. The Hydraulic Retention Time (HRT) was $6 \mathrm{~h}$. The reactor operated in successive cycles of $3 \mathrm{~h}$ each. One cycle consisted of 5 min influent addition, 162-167 min aeration (depending on the settling time changing), 2-7 min settling (changing during the initial cultivation) and 6 min effluent withdrawal. Air was introduced in the reactor from the bottom, using a sparger, at a superficial air velocity of $2.25 \mathrm{~cm} / \mathrm{s}(3 \mathrm{~L} / \mathrm{min})$. The air-flow was monitored using a flow meter but DO control was not applied. The operations were regulated by a PLC (programmable logic controller).

In order to accurately modify the Volumetric Loading Rate (VLR) and the $C / N$ ratio, the experiment was carried-out with synthetic wastewater. The synthetic wastewater had the general composition described by Beun et al. (2002). In order to change the $C / N$ ratio, the Sodium Acetate and/or $\mathrm{NH}_{4} \mathrm{Cl}$ concentrations were changed.

\subsection{Experimentation phases}

The whole experimentation lasted 212 days and was divided into two different periods:

Table 1

Operational condition during the period 1 (cultivation).

\begin{tabular}{|c|c|c|c|c|c|c|}
\hline \multirow[t]{2}{*}{ Day } & \multicolumn{3}{|l|}{$\mathrm{R} 1$} & \multicolumn{3}{|l|}{$\mathrm{R} 2$} \\
\hline & $\begin{array}{l}T_{\mathrm{s}} \\
\min \end{array}$ & $\begin{array}{l}\text { VLR } \\
\mathrm{kg} / \mathrm{m}^{3} \mathrm{~d}\end{array}$ & Configuration & $\begin{array}{l}T_{\mathrm{s}} \\
\min \end{array}$ & $\begin{array}{l}\text { VLR } \\
\mathrm{kg} / \mathrm{m}^{3} \mathrm{~d}\end{array}$ & Configuration \\
\hline $1 \mathrm{st}-7 \mathrm{th}$ & 7 & 2.4 & SBAR & 5 & 2.4 & SBAR \\
\hline 8th-14th & 5 & & & 4 & & \\
\hline 15th-28th & 3 & & & 3 & & \\
\hline 29th-32nd & 2 & & & 2 & & \\
\hline 33th-101st & & & & & 4.8 & \\
\hline 102nd-128th & & & SBBC & & & SBBC \\
\hline
\end{tabular}


Table 2

Operational condition during the period 2 .

\begin{tabular}{|c|c|c|c|c|c|c|c|}
\hline \multirow[t]{2}{*}{ Day } & & \multicolumn{3}{|l|}{$\mathrm{R} 1$} & \multicolumn{3}{|l|}{$\mathrm{R} 2$} \\
\hline & & $\begin{array}{l}Q_{\text {air }} \\
\mathrm{L} / \mathrm{min}\end{array}$ & $\begin{array}{l}\text { VLR } \\
\mathrm{kg} / \mathrm{m}^{3} \mathrm{~d}\end{array}$ & $\begin{array}{l}C / N \\
- \\
\end{array}$ & $\begin{array}{l}Q_{\text {air }} \\
\mathrm{L} / \mathrm{min}\end{array}$ & $\begin{array}{l}\text { VLR } \\
\mathrm{kg} / \mathrm{m}^{3} \mathrm{~d}\end{array}$ & $\begin{array}{l}C / N \\
- \\
\end{array}$ \\
\hline 129th-149th & Sub-period I & 3 & 3.6 & $8 / 1$ & 3 & 3.6 & $8 / 1$ \\
\hline 150th-170th & Sub-period II & 3 & 4.8 & $8 / 1$ & 3 & 4.8 & $8 / 1$ \\
\hline 171st-181th & Sub-period III & 2 & 4.8 & $16 / 1$ & 2 & 4.8 & $16 / 1$ \\
\hline 182nd-191st & Sub-period III & 3 & 4.8 & $16 / 1$ & 3 & 4.8 & $16 / 1$ \\
\hline 192nd-202nd & Sub-period IV & 2 & 4.8 & $16 / 1$ & 2 & 4.8 & $16 / 1$ \\
\hline 203th-212nd & Sub-period IV & 3 & 4.8 & $16 / 1$ & 3 & 4.8 & $16 / 1$ \\
\hline
\end{tabular}

- Period 1: granular sludge cultivation.

- Period 2: pseudo-stationary working.

During Period 1 (lasting 128 days), the granular sludge was cultivated in two SBAR reactors, using different operational conditions, in order to obtain a different mean granule size in the two systems. Both reactors, named "R1" and "R2", were started with aerobic sludge collected from the aeration tank of the Palermo municipal plant. The concentration of Total Suspended Solids (TSS) in the sludge inoculum was $4 \mathrm{~g} / \mathrm{L}$ (with a initial Sludge Volume Index of $\mathrm{SVI}_{30}=140 \mathrm{~mL} / \mathrm{g}$ and $\mathrm{SVI}_{10}=194 \mathrm{~mL} / \mathrm{g}$ ). Only the settling time $\left(t_{\mathrm{s}}\right)$ and the VLR were changed in the two reactors. In particular, the $t_{\mathrm{s}}$ was reduced from 7 to $3 \mathrm{~min}$ in R1 during the first 2 weeks of operation (reducing 2 min per week), in order to let the biomass acclimatize and prevent a massive wash-out (Qin et al., 2004a,b; Torregrossa et al., 2007). On the other hand, in R2 the $t_{\mathrm{s}}$ was reduced from 5 to $3 \mathrm{~min}$ in the first 2 weeks (reducing $1 \mathrm{~min}$ per week). The settling time was further reduced to $2 \mathrm{~min}$ in both reactors, after 28 days. The value of the VLR applied was $2.4 \mathrm{kgCOD} /$ $\mathrm{m}^{3} \mathrm{~d}$ during the first 32 days in both reactors. At the 33rd day, this value was doubled in the reactor $\mathrm{R} 2\left(4.8 \mathrm{kgCOD} / \mathrm{m}^{3} \mathrm{~d}\right)$. This choice allowed us to obtain granules of different sizes (which is the final goal of different cultivation strategies), in accordance with Li et al. (2008). The Period 2 was divided into four sub-periods (I-IV), lasting 21 days each. In particular, the aim of this period was to analyze the variation in the anoxic and aerobic layer inside the granules and the simultaneous organic matter and nitrogen removal performance relating to different operational conditions and different granule sizes. Mainly, the effects of VLR and $C / N$ ratios were studied. In general, in order to obtain a good SND process the $C / N$ ratio was kept meanly high $(\mathrm{mgCOD} / \mathrm{mgN}>8: 1)$. During the sub-period I the $C / N$ ratio was maintained identical in both reactors (8:1), while the VLR was changed: in the R1 was increased from 2.4 to $3.6 \mathrm{kgCOD} / \mathrm{m}^{3} \mathrm{~d}$; in the $\mathrm{R} 2$ the VLR was reduced from 4.8 to $3.6 \mathrm{kgCOD} / \mathrm{m}^{3} \mathrm{~d}$. In this conditions, in the bulk liquid the Oxidation Reduction Potential (ORP) values ranged from $-50 \mathrm{mV}$ (anoxic conditions) at 70-80 $\mathrm{mV}$ (aerobic conditions), due to the effect of the phases of feast and famine.

During the sub-period II, the VLR was increased again to $4.8 \mathrm{kgCOD} / \mathrm{m}^{3} \mathrm{~d}$ in both reactors, the $C / N$ ratio and DO concentration were kept constant. This was done in order to analyze the removal performance in $\mathrm{R} 1$ with a gradual VLR increase $(2.4 \mathrm{kgCOD} /$ $\mathrm{m}^{3} \mathrm{~d}$ at the $102 \mathrm{nd}$ day, $3.6 \mathrm{kgCOD} / \mathrm{m}^{3} \mathrm{~d}$ at the 129 th day and $4.8 \mathrm{kgCOD} / \mathrm{m}^{3} \mathrm{~d}$ at the 150th day). In the sub-periods III and IV, the VLR was kept constant while the $C / N$ ratio was doubled. Finally, in order to analyse the effect in the famine and feast periods during the SND process, the air flow was reduced in the first part of both sub-periods. More specifically, the air flow was maintained constant $\left(Q_{\mathrm{a} 1}=3 \mathrm{~L} / \mathrm{min}\right)$ during the whole experiment; only in two periods, between the 171st-181st and the 192nd-202nd day, the air flow was temporarily reduced at $Q_{\mathrm{a} 2}=2 \mathrm{~L} / \mathrm{min}$. Actually, there is not a substantial difference in the two sub-periods III and IV in term of operational conditions. In fact, it could define a single period of 42 days (from the 171st to the 212nd day) alternating with two periods in which the air flow was reduced (days 171-181 and 192-202). The sub-period IV was repeated only to validate the data obtained in the previous period. In Tables 1 and 2 the operational conditions during period 1 and 2 are summarized.

(a)

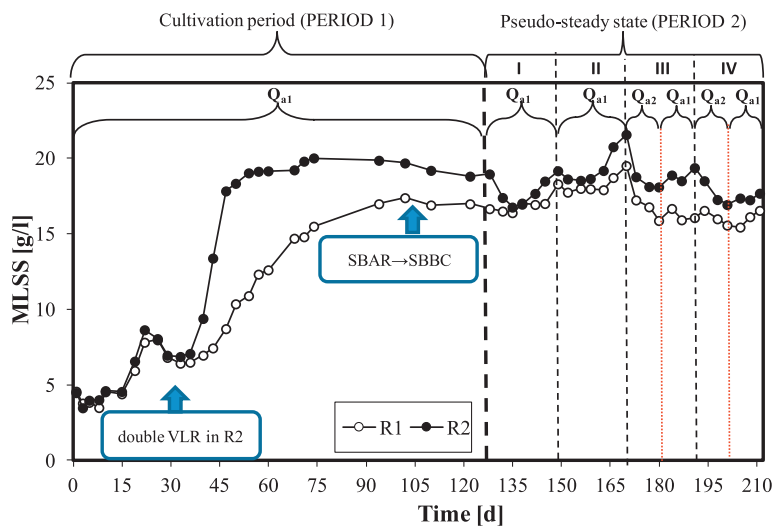

(b)

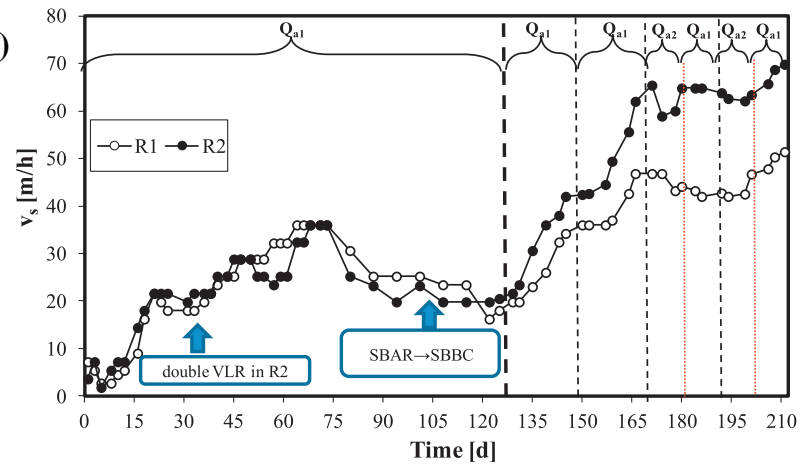

(c)

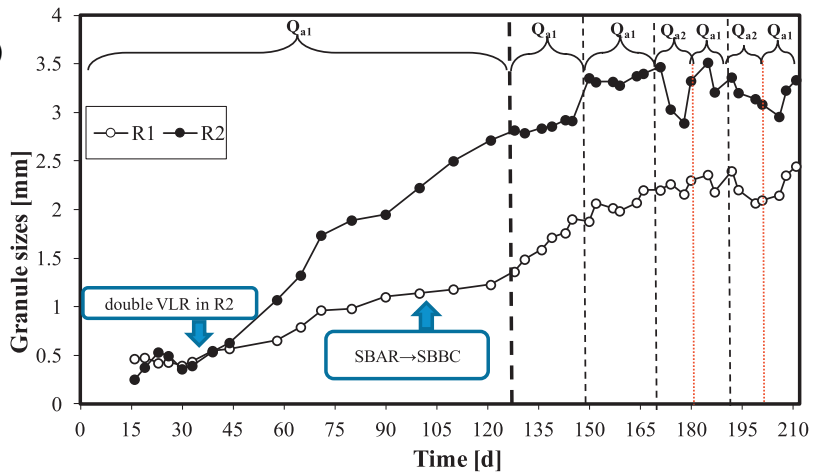

Fig. 2. Trend of (a) MLSS concentration, (b) settlement velocity of granular sludge, and (c) mean granular sizes during the experimental campaign. 


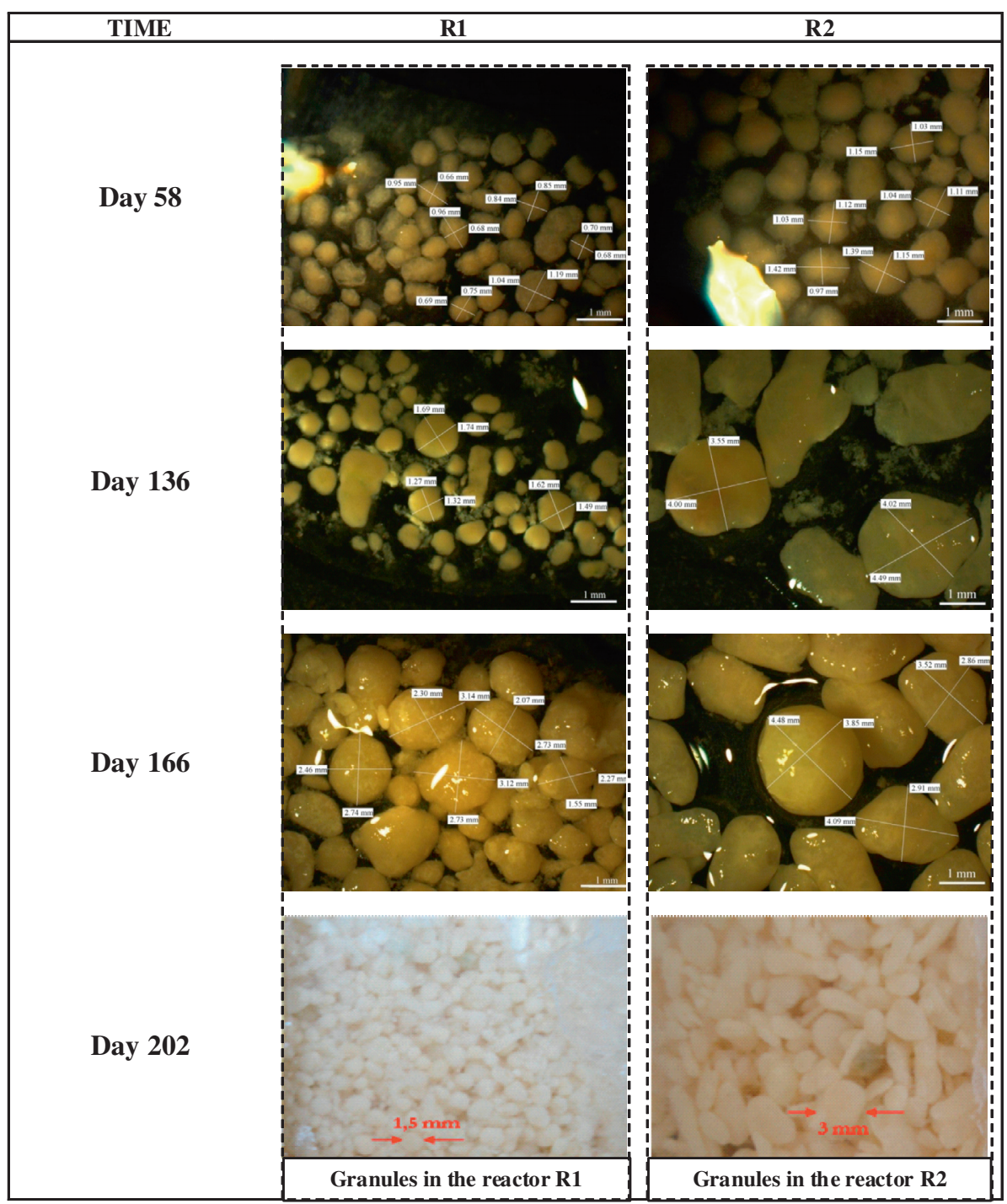

Fig. 3. Stereo-microscopic pictures of granules in R1 and R2 during the experimentation.

\subsection{Analytical procedures}

The chemical-physical analysis was performed according to standard methods (APHA-AWWA-WEF, 1998): in particular, COD, TSS, $\mathrm{NH}_{4}-\mathrm{N}, \mathrm{NO}_{3}-\mathrm{N}, \mathrm{P}_{\mathrm{TOT}}$ were measured. The settleability of the granular sludge was evaluated analyzing the settling curves. Further, in order not to "disturb" the granular sludge formation, the SVI analysis was carried-out every 2 weeks. The granules sizes were studied by digital image capture. In particular, the granule observations were carried-out through a scanning optical microscope and a stereo-microscope (with different enlargement, depending on the granule sizes). The mean granule sizes were obtained by measuring about 800 granules, using an image analyzer. The specific volume of mixed liquor sample was variable $(5-50 \mathrm{~mL})$ relating to granule sizes. All analysis were carried out twice a week.

\section{Results}

\subsection{Sludge granulation in various phases}

Fig. 2 shows the TSS concentrations trends in the mixed liquor (MLSS), the settlement velocity $\left(v_{\mathrm{s}}\right)$ and the mean granule sizes during the whole experimentation.
As shown in Fig. 2(a), MLSS concentration increased differently in the two granular sludge. After the VLR variation in $\mathrm{R} 2$ to the 33rd day, the biomass in the reactor $\mathrm{R} 2$ grew more rapidly than the biomass in R1. After the 90th day a consistent sludge accumulation formed periodically within the riser in both SBARs. This cake of granular sludge was removed with difficulty from the aeration. Furthermore, due to high SS concentrations periodical sludge wash-out occurred. For this reason, during the 102 nd day the SBAR configuration in both reactors were changed to SBBC.

Relating to Period 2, the MLSS growth in the two reactors was closely linked to the changed set of operating parameters. In particular, the change of VLR after 128 days caused a partial breakdown of some granules in R2. Consequently, a part of TSS was washed away. Contrarily, the increase of VLR in R1 did not have any immediate results. The subsequent increase in the sub-period II, induced a small increase in the TSS concentration in both reactors. The influence of air flow variations in the sub-periods III and IV were important. In general, a temporary wash-out occurred when air flow was decreased.

As shown in the Fig. 2b, the sludge settle-ability generally increases. After the 20th days, the SVI was less than $90 \mathrm{~mL} / \mathrm{g}$, reaching values below $40 \mathrm{~mL} / \mathrm{g}$ during the 70th day. Nevertheless, even if the settleability was always good, the trends reported in Fig. $2 \mathrm{~b}$ show a significant decrease of $v_{\mathrm{s}}$ after the 70th day in both reactors. 

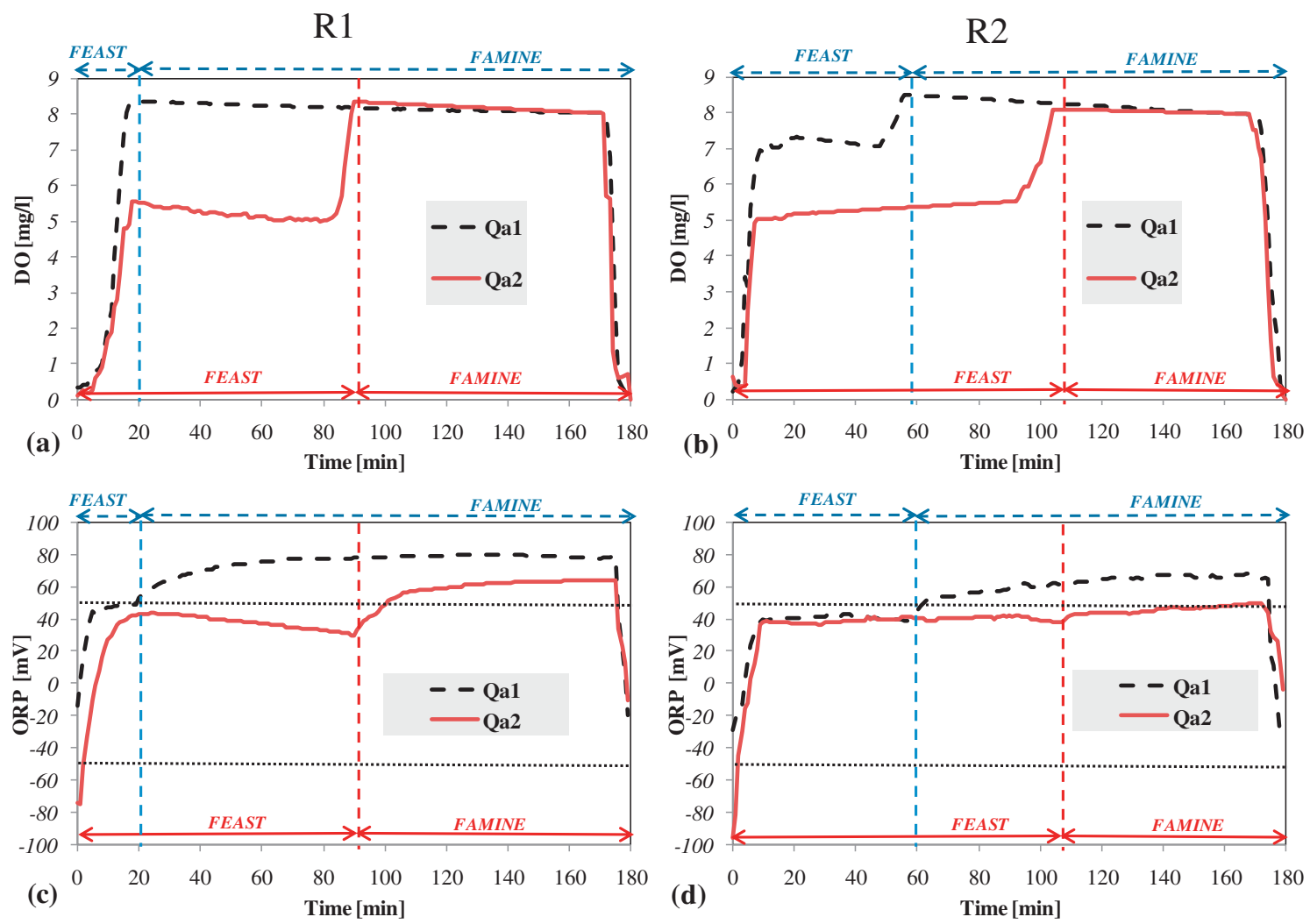

Fig. 4. DO concentration (a, b) of and ORP (c, d) during a cycle of R1 and R2 under different operational conditions.

This circumstance was caused by the large dimension of granules in the sludge connected with the presence of riser in the reactor. Also for this reason, as discussed above, the reactor configuration was changed and consequently the $v_{\mathrm{S}}$ increased again. In fact, after the configuration change, from SBAR to SBBC, there was not any negative interaction between big granules and riser.

However, the difference in the $v_{\mathrm{s}}$ between R1 and R2 was observed only after the 130 th days, three week after the configuration change. The granular sludge in $\mathrm{R} 2$ has shown a better settleability than the sludge in $\mathrm{R} 1$, reaching $60 \mathrm{~m} / \mathrm{h}$. This fact can be attributed to the different granule sizes.

Finally, in Fig. 2c the trend of mean granule size in the two granular sludge is reported. The results show that the granular dimensions in both reactor were comparable until the 33rd day. Then, the different strategy of cultivation in terms of $t_{\mathrm{s}}$ variation, did not affect the granular sizes when the DO concentration is high. On the contrary, the variation of VLR in R2 (day 33) strongly influenced the granule formation and the granule sizes increase faster than in R1. On the 120th day the mean granular size in R2 was double the R1 one. During Period 2, the granule growth was related to the VLR variation and operational condition. In particular, when the air flow in the reactor decreased (sub-periods III and IV) the granules were broken and the mean granule size decreased. In Fig. 3 the stereo-microscopic pictures of granules are shown.

\subsection{Effect of air flow reduction on the feast and famine phases}

During Period 2 much attention has been given to the analysis of feast and famine periods, relating to the variation of operational condition (mainly alternating $Q_{\text {air }}$ reduction during sub-periods III and IV). In particular the oxygen penetration was indirectly investigated observing the bulk liquid composition and its effect on the $\mathrm{N}$-removal efficiency. In general, the end of the feast period and the subsequent beginning of the famine period can be easily identified in terms of oxygen consumption, which decreases in few minute after the feast condition. More in detail, the length of the feast period depends on oxygen penetration and organic substrate availability for the micro-organisms in the different granule layers. According to McSwain and Irvine (2008), after the feast period the DO concentration in the bulk reaches its max value because the substrate is completely consumed. In particular, it is important underline that the famine conditions only refer to organic matter consumers (fast oxygen uptakes). Similarly for the "Feast" conditions (slow oxygen uptakes).

Fig. 4a and b report two examples of DO concentration versus time curves in the $\mathrm{R} 1$ and $\mathrm{R} 2$ reactors during different cycles in the sub-periods III. The analyses were carried-out on the 178th day $\left(Q_{\mathrm{a} 2}\right)$ and 187 th day $\left(Q_{\mathrm{a} 1}\right)$. In particular, with $Q_{\mathrm{a} 1}$ the feast period lasted about 20 min in R1 and about 58 min in R2. With $Q_{\mathrm{a} 2}$ a lower DO concentration was guaranteed in the initial phase of the cycle and consequently the feast period length increased. The difference in the feast and famine period length between reactors was due to different granule sizes because the test was realized in similar operational conditions (without oxygen control).

Fig. $4 \mathrm{c}$ and $\mathrm{d}$ report the ORP measurement during the same cycles. The measurements were realized in the bulk liquid and, despite not being a direct measurement of the internal zone of the granules, they are very interesting for N-removal (Yuan and Gao, 2010). In general, the aerobic or anoxic/anaerobic condition in the bulk results from the internal processes in the granule and different conditions may occurred even if the DO in the bulk is not zero (Mosquera-Corral et al., 2005; Li et al., 2008). More specifically, if the ORP value is higher than $50 \mathrm{mV}$ an aerobic oxidation occurs; on the other hand, values lower than $-50 \mathrm{mV}$ denote an anaerobic condition. Finally, if the ORP ranges between 50 and $-50 \mathrm{mV}$ an anoxic processes occurs. In general, at smaller sizes 
(a)

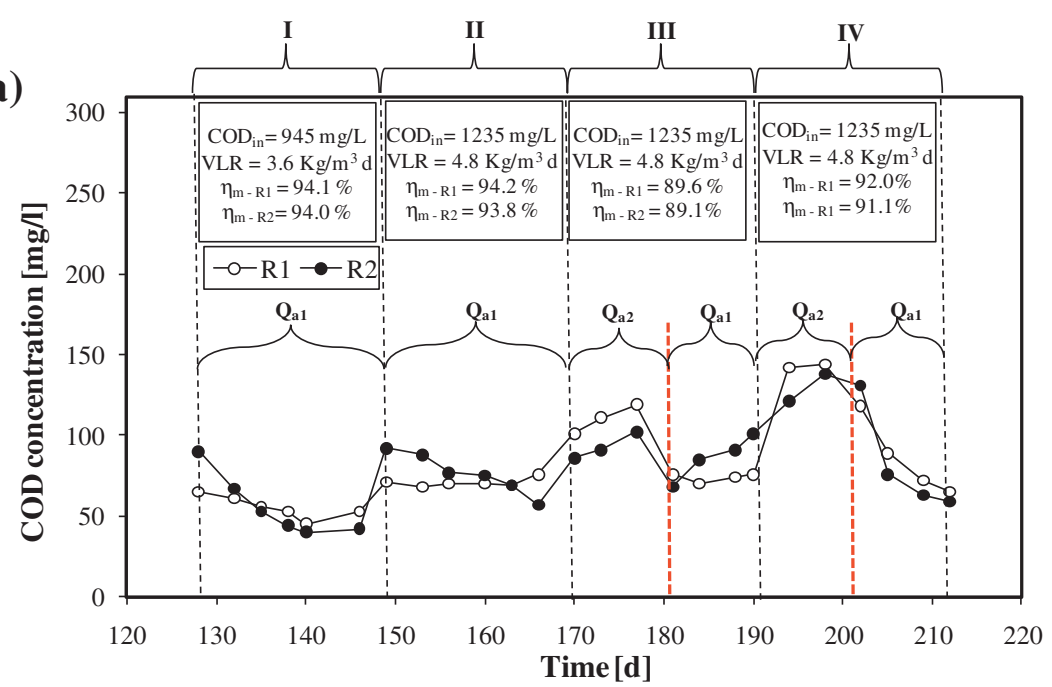

(b)

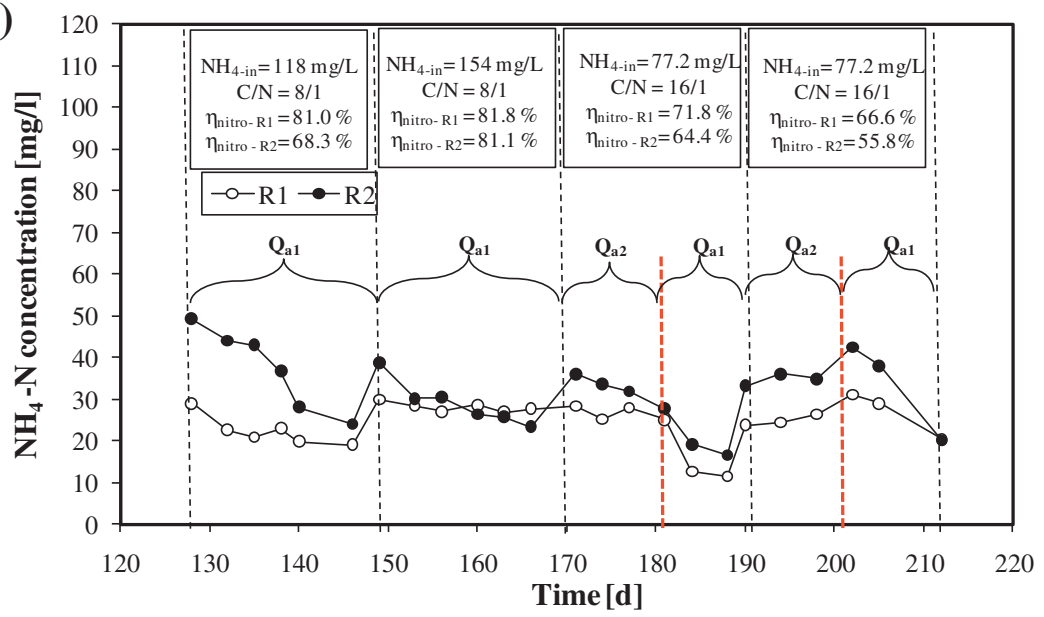

(c)

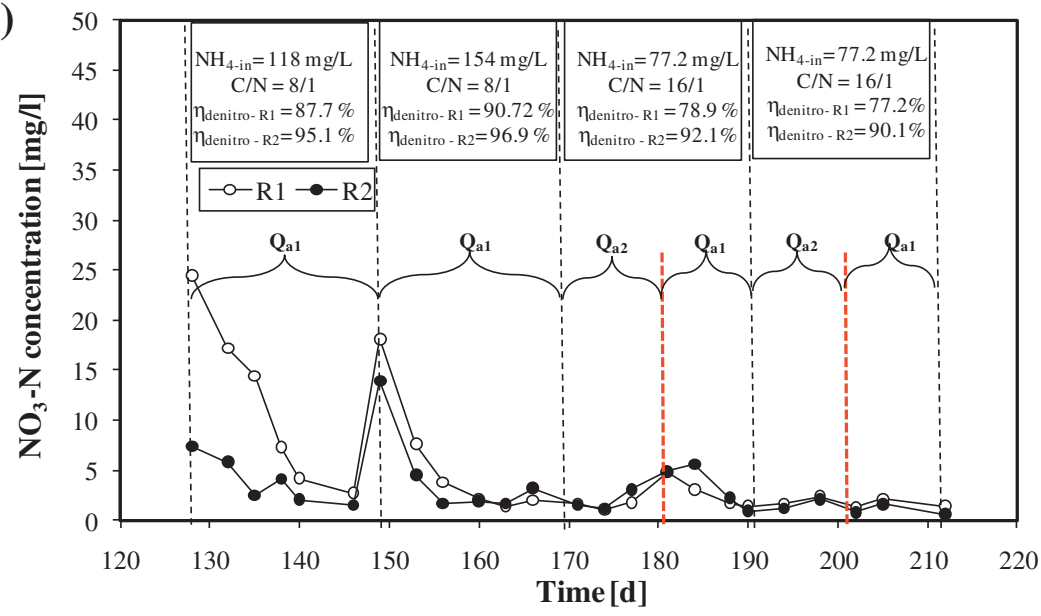

Fig. 5. Trend of (a) $\mathrm{COD}$, (b) $\mathrm{NH}_{4}-\mathrm{N}$, and (c) $\mathrm{NO}_{3}-\mathrm{N}$ concentrations in the effluent of $\mathrm{R} 1$ and $\mathrm{R} 2$.

the oxygen penetration occurs deeper, so anoxic conditions are not that long. With higher sizes, anoxic reactions can occur longer in the middle of the aggregate while oxygen is penetrating, so aerobic and anoxic conditions coexists. Furthermore, ammonium was not zero, so oxygen was being consumed by nitrifies.

\subsection{Organic and nitrogen removal}

Removal performances were evaluated after the cultivation period.
As shown in Fig. 5a, in the sub-period I, the COD removal was excellent in both reactors, with values of COD discharge less than $60 \mathrm{mg} / \mathrm{L}$ (organic performance removal 94\%).

During the sub-period II, characterized by a VLR increase, the performance of COD removal was similar, despite COD concentrations in the influent increased until $1235 \mathrm{mg} / \mathrm{L}$. The reduction of air flow in the first phase of sub-period III, caused a partial disintegration of granules and a consequential COD increase in the effluent. This circumstance could be attributed to: (1) shear stress reduction; (2) DO reduction during the feast period. Consequently the 

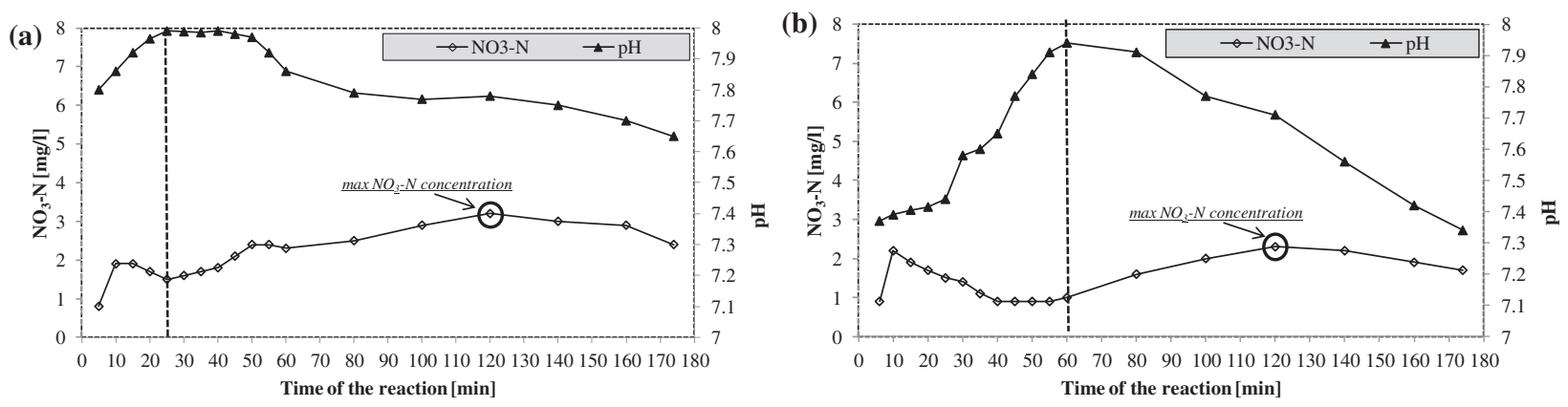

Fig. 6. Trends of $\mathrm{pH}$ and $\mathrm{NO}_{3}-\mathrm{N}$ in $\mathrm{R} 1$ (a) and $\mathrm{R} 2$ (b) under high $\mathrm{DO}$ concentration.

COD concentration in the effluent slightly increased. A similar phenomenon occurred in the first phase of sub-period IV when the air flow again decreased.

Regarding to ammonium and nitrate removal, in the Fig. 5b and $\mathrm{c}$ the trend of ammonium and nitrate concentration in the effluent are shown. In the sub-period I the mean total N-removal was acceptable: about $80 \%$ in $\mathrm{R} 1$ and $70 \%$ in R2. On the contrary, the denitrification process was better in $\mathrm{R} 2$ than $\mathrm{R} 1$. This circumstance was due to the different granule size in the sludge, and consequently to different thicknesses of aerobic and anoxic layers, according to previous observation. In the sub-period II the ammonium concentration in the influent was increased contemporarily with the COD increase. The results underlined a good nitrification performance in both reactors despite the high ammonium concentration in the influent. The denitrification process also remains satisfactory despite the high DO concentration in the bulk. Similarly, the nitrification rates were maintained (indeed improved slightly after the initial phase) and the temporary nitrate rose up was due to increase of ammonium concentration in the influent. In general, the good performance of nitrification processes were confirmed in the sub-period III and IV. However, nitrification efficiency decreased in both reactors after air flow reduction, due to the lower depth of gas diffusion within the granules (Okabe et al., 1995). In particular, the reduction of air flow influenced the nitrification process mainly in the granules of $\mathrm{R} 2$ due to a greater reduction in the oxygen diffusion than R1 granules. In this context, the decrease of air flow, and consequently of DO concentration, did not result in a significant improvement of denitrification efficiency. In fact, even though ammonium increased, the system was already able to cope with it and there are not any advantage when oxygen concentration decreased. This could be due to the granule sizes obtained in our experiments that were stable and bigger than $1.5 \mathrm{~mm}$ in both reactors, after the cultivation period (see Fig. 2c); consequently, the good stratification guaranteed an important anoxic layer also with $Q_{\mathrm{a} 1}$. The results obtained in sub-period IV, confirmed the previous observations.

The biological $\mathrm{N}$-removal processes during the whole cycles were also monitored using $\mathrm{pH}$ and $\mathrm{NO}_{3}-\mathrm{N}$. The changes in aqueous chemical composition during the typical real time control cycle are shown in Fig. 6. The analysis was carried out in the second phase of sub-period III, on the 187 th day with air flow equal to $Q_{a 1}$.

The $\mathrm{pH}$ value initially increased during the feast period, and then decreased during the famine period.

The phase of the processes of denitrification and nitrification can be identified when the pH changes from an increasing to a decreasing trend. In fact, although the $\mathrm{pH}$ changes in slope indicate only which reaction is the dominant one (but they can still coexist), the analysis of nitrate end $\mathrm{pH}$ profiles during the whole cycle can be useful. More specifically, in accordance with Wan et al. (2009), the denitrification process generated alkalinity causing the raise of $\mathrm{pH}$. On the other hand, during the nitrification the
$\mathrm{pH}$ gradually declined because the oxidation of ammonium consumes alkalinity. Thus, the bending point in $\mathrm{pH}$ and the changing point in the nitrate curve represent the end of the denitrification stage and the start-up of the nitrification processes. In this context, it is important underline that the presence of nitrate during the initial phase of the cycle is the results of nitrate concentration residual of the previous cycle, more specifically of the last part of the previous cycle, where the nitrification is the dominant process. As shown from the graphs, in both reactor the feast and famine period practically coincides with the dominant process of denitrification and nitrification processes, respectively. Actually, the trend of $\mathrm{pH}$ and their strong variation (increase and decrease) or partial stabilization, depend on the competition of denitrified and nitrified factor, and the dominant processes defines only the condition in the bulk liquid. However, this situation is in agreement with other results reported in the literature (de Kreuk et al., 2007): in the feast period the nitrification hardly occurs because the oxygen cannot penetrate deeper into the granules due to the high demand of heterotrophic organisms in the outer layer. Consequently, the anoxic layer becomes larger. Subsequently, in the famine period the nitrate concentration increases because the oxygen demand of heterotrophic bacteria decreases.

\section{Conclusion}

The authors observed the SND process in two aerobic granular SBRs. The granular sludge was cultivated under different operational conditions. Because high mean granule sizes were achieved in both plants, the two plants showed a satisfactory SND, with efficiency $>90 \%$ for both carbon and nitrogen removal. In particular, the data show that the SND can occur satisfactorily with high oxygen concentrations. Nevertheless, the specific performance in $\mathrm{N}$-removal was strongly correlated with granule sizes. It is also interesting the granules breaking was always negligible, although the particle size of granules was greater than $1.5 \mathrm{~mm}$ for a long experimental time.

\section{Acknowledgement}

The authors want to thank Eng. Fabio Corsino for their precious help with pilot plant operation.

\section{References}

Abdullah, N., Yuzir, A., Curtis, T.P., Yahya, A., Ujang, Z., 2013. Characterization of aerobic granular sludge treating high strength agro-based wastewater at different volumetric loadings. Bioresour. Technol. 127, 181-187.

Adav, S.S., Lee, D.J., Show, K.Y., Tay, J.H., 2008. Aerobic granular sludge: recent advances. Biotechnol. Adv. 26, 411-423.

Anuar, A., Nor, A., Ujang, Z., van Loosdrecht, M.C.M., de Kreuk, M.K., 2007. Settling behavior of aerobic granular sludge. Water Sci. Technol. 56, 55-63.

APHA-AWWA-WEF, 1998. Standard Methods for the Examination of Water and Wastewater, twentieth ed. American Public Health. 
Beun, J.J., Heijnen, J.J., van Loosdrecht, M.C.M., 2001. N-removal in a granular sludge sequencing batch airlift reactor. Biotechnol. Bioeng. 75, 82-92.

Beun, J.J., Heijnen, J.J., van Loosdrecht, M.C.M., 2002. Aerobic granulation in a sequencing batch airlift reactor. Water Res. 36, 702-712.

Chen, F.Y., Liu, Y.Q., Tay, J.H., Ning, P., 2011. Operational strategies for nitrogen removal in granular sequencing batch reactor. J. Hazard. Mater. 189, 342-348.

Coma, M., Verawaty, M., Pijuan, M., Yuan, Z., Bond, P.L., 2012. Enhancing aerobic granulation for biological nutrient removal from domestic wastewater. Biores. Technol. 103, 101-108.

de Kreuk, M.K., van Loosdrecht, M.C.M., 2004. Selection of slow growing organisms as a means for improving aerobic granular sludge stability. Water Sci. Technol. 49, 9-17.

de Kreuk, M.K., van Heijnen, J.J., Loosdrecht, M.C.M., 2005. Simultaneous COD, nitrogen and phosphate removal by aerobic granular sludge. Biotechnol. Bioeng. 90, 761-769.

de Kreuk, M.K., Kishida, N., van Loosdrecht, M.C.M., 2007. Aerobic granular sludge State of art. Water Sci. Technol. 155, 75-81.

Jin, R.C., Zhenga, P., Mahmooda, Q., Zhanga, L., 2008. Performance of a nitrifying airlift reactor using granular sludge. Sep. Purif. Technol. 63, 670-675.

Kim, I.S., Kim, S.M., Jang, A., 2008. Characterization of aerobic granules by microbial density at different COD loading rates. Bioresour. Technol. 99, 1825.

Li, Y., Liu, Y., Shen, L., Chen, F., 2008. DO diffusion profile in aerobic granule and its microbiological implications. Enzyme Microb. Technol. 43, 349-354.

Liu, Y.Q., Tay, J.H., 2006a. Cultivation of aerobic granules in a bubble column and an airlift reactor with divided draft tubes at low aeration rate. Biochem. Eng. J. 34 $1-7$.

Liu, Y.Q., Tay, J.H., 2006b. Variable aeration in sequencing batch reactor with aerobic granular sludge. J. Biotechnol. 124, 338-346.

Liu, Y.Q., Tay, J.H., 2008. Influence of starvation time on formation and stability of aerobic granules in sequencing batch reactors. Bioresour. Technol. 99, 980-985.
McSwain, B.S., Irvine, R.L., 2008. Dissolved oxygen as a key parameter to aerobic granule formation. Water Sci. Technol. 58, 781-787.

Mosquera-Corral, A., de Kreuk, M.K., Heijnen, J.J., van Loosdrecht, M.C.M., 2005. Effects of oxygen concentration on N-removal in an aerobic granular sludge reactor. Water Res. 39, 2676-2686.

Okabe, S., Hirata, K., Watanabe, Y., 1995. Dynamic changes in spatial microbial distribution in mixed-population biofilms: experimental results and model simulation. Water Sci. Technol. 32, 67-74.

Othman, I., Anuar, A.N., Ujang, Z., Rosman, N.H., Harun, H., Chelliapan, S., 2013. Livestock wastewater treatment using aerobic granular sludge. Bioresour. Technol. 133, 630-634.

Qin, L., Tay, J.H., Liu, Y, 2004a. Aerobic granular sludge cultivated under the selective pressure as a driving force. Process Biochem. 39, 557-563.

Qin, L., Tay, J.H., Liu, Y., 2004b. Selection pressure is a driving force of aerobic granulation in sequencing batch reactors. Process Biochem. 39, 579-584.

Torregrossa, M., Di Bella, G., Viviani, G., Gnoffo, A., 2007. Performances of a granular sequencing batch reactor (GSBR). Water Sci. Technol., 125-133.

Wan, J., Sperandio, M., 2009. Possible role of denitrification on aerobic granular sludge formation in sequencing batch reactor. Chemosphere 75, 220-227.

Wan, J., Bessiere, Y., Sperandio, M., 2009. Alternating anoxic feast/aerobic famine condition for improving granular sludge formation in sequencing batch airlift reactor at reduced aeration rate. Water Res. 43, 5097-5108.

Wei, Y., Li, G., Wang, B., 2011. Application of granular sludge membrane bioreactor in the treatment of wastewater. Procedia Environ. Sci. 10, 108-111.

Yang, S.F., Liu, Y., Tay, J.H., 2003. A novel granular sludge sequencing batch reactor for removal of organic and nitrogen from wastewater. J. Biotechnol. 106, 77-86.

Yilmaz, G., Lamaire, R., Keller, J., Yuan, Z., 2008. Simultaneous nitrification, denitrification and phosphorus removal from nutrient-rich industrial wastewater using granular sludge. Biotechnol. Bioeng. 100, 529-541.

Yuan, X., Gao, D., 2010. Effect of oxygen on nitrogen removal and process control in aerobic granular sludge reactor. J. Hazard. Mater. 178, 1041-1045. 